"further investigation required" (15), and "clinical correlation required" (8). Although all radiologists failed to stage some scans, three were responsible for the majority (30 scans, 70\%).

Conclusions Our results show that a significant proportion of scan reports fell below the recommended EANM standards either in the description of FDG accumulation or matching those patterns to SUV. Furthermore, many scans were unstaged, diminishing their value to the commissioning MDT. Closer liaison between IS radiologists and MDT members may assist the reporting process to ensure the maximum value is obtained from this expensive test for the benefit of this unfortunate patient group.

\section{P183 COMPARISON OF PATIENT SATISFACTION BETWEEN ENDOBRONCHIAL ULTRASOUND AND FLEXIBLE BRONCHOSCOPY PERFORMED UNDER CONSCIOUS SEDATION: A PROSPECTIVE STUDY}

doi:10.1136/thoraxjnl-2011-201054c.183

${ }^{1} \mathrm{~S}$ Huq, ${ }^{1} \mathrm{C}$ Smyth, ${ }^{1} \mathrm{~S}$ Kazmi, ${ }^{2} \mathrm{~T}$ Giles, ${ }^{1} \mathrm{M}$ Walshaw, ${ }^{1} \mathrm{~S}$ Binukrishnan, ${ }^{1} \mathrm{~K}$ Mohan. ${ }^{1}$ Liverpool Heart and Chest Hospital NHS Foundation Trust, Liverpool, UK; ${ }^{2}$ Royal Liverpool and Broadgreen University Hospitals NHS Trust, Liverpool, UK

Background Endobronchial ultrasound-guided transbronchial needle aspiration (EBUS-TBNA) is increasingly performed by respiratory physicians across the UK. Although patient satisfaction with flexible bronchoscopy (FB) is high, there are no studies comparing patient satisfaction with FB vs EBUS performed under conscious sedation.

Methods In this prospective study, patients completed a questionnaire $2 \mathrm{~h}$ post-procedure when they were fully awake as determined by the modified Aldrete score. The questionnaire consisted of a 4-point Likert scale to record the degree of discomfort and a 5point scale to record the overall satisfaction and willingness to return for the procedure. Both EBUS and FB were performed using topical lignocaine and intravenous midazolam. EBUS was performed by a consultant physician, whereas FB was performed by a consultant physician or a specialty registrar.

Results 52 consecutive patients (mean age 65) undergoing EBUS and 35 patients (mean age 66) undergoing FB completed the study. Although the mean dose of intravenous midazolam used in the EBUS group was higher ( $3.16 \mathrm{mg}$ vs $2.52 \mathrm{mg} ; \mathrm{p}<0.01$ ), the level of sedation (determined by sedation score of 0 -unresponsive to 6-agitated) prescope insertion was similar in both groups. The mean dose of topical lignocaine (excluding oropharyngeal lignocaine) was also similar in both groups. The duration of procedure with EBUS was longer compared to FB (21.25 min vs 12.09 min; $p<0.001)$. Despite this, there were no significant differences in the reported patient discomfort with anaesthetic throat spray, transtracheal lignocaine injection or scope insertion. Similarly, there were no significant differences in the reported incidence of cough, dyspnoea, throat pain, chest pain, feeling of suffocation and overall tolerance of the procedure. The overall satisfaction for the procedure was $95 \%$ in the EBUS group and $89 \%$ in the FB group, while $92 \%$ and $86 \%$ respectively were willing to have the procedure again if needed. EBUS was diagnostic in $96 \%$ (mean lymph node size $1.6 \mathrm{~cm}$ ) and there were no complications.

Conclusion Patient satisfaction with EBUS-TBNA under conscious sedation is high. As EBUS services continue to expand, physicians can perform this under conscious sedation with similar patient satisfaction level as experienced with FB.

\section{P184 IDENTIFYING LEARNING STRATEGIES USED BY RESPIRATORY TRAINEES IN BRONCHOSCOPY}

doi:10.1136/thoraxjnl-2011-201054c.184

S Wiscombe. Newcastle Upon Tyne Teaching Hospitals NHS Trust, Newcastle, UK

Introduction and Objectives Medical bronchoscopy is a key skill for respiratory physicians taking years to achieve competency. The
Abstract P184 Table 1 Summary of themes identified from trainee questionnaires and focus group discussion

\begin{tabular}{|c|c|}
\hline $\begin{array}{l}\text { KEY THEMES IDENTIFIED BY TRAINEES IN QUESTIONNAIRES AND } \\
\text { DISCUSSION }\end{array}$ & D FOCUS GROUP \\
\hline $\begin{array}{l}\text { Recognition that trainees may learn differently: } \\
-\quad \text { Role of tools to address this: books, CD ROM, virtual-tour, videos, courses etc } \\
-\quad \text { Comparison to how other specialities learn similar complex skills }\end{array}$ & \\
\hline $\begin{array}{l}\text { Bronchoscopy courses/simulation: } \\
\text { - In general felt to be helpful in increasing knowledge, confidence } \\
\text { - } \quad \text { Provides ideal 'framework' } \\
\text { - } \quad \text { Decreases anxiety of early procedures on 'real' patient } \\
\end{array}$ & \\
\hline $\begin{array}{l}\text { How do trainees increase learning from experience (largest theme): } \\
\text { - } \quad \text { Standardised approach, particularly at the beginning of training } \\
\text { - } \quad \text { Breakdown of the skill in to component parts } \\
\text { - } \quad \text { Reflanations from trainers } \\
\text { - }\end{array}$ & \\
\hline $\begin{array}{l}\text { Helpful trainer behaviours encountered in training: } \\
-\quad \text { Specific feedback } \\
-\quad \text { Help with problem solving } \\
-\quad \text { Prioritising teaching over service provision }\end{array}$ & \\
\hline $\begin{array}{l}\text { Unhelpful trainer behaviours encountered in training: } \\
-\quad \text { Multiple changes to technique within short succession } \\
-\quad \text { Not being 'allowed' to attempt more difficult aspects of bronchoscopy } \\
\text { - Lack of feedback leading to reduced trainee confidence }\end{array}$ & \\
\hline $\begin{array}{l}\text { Environmental factors in training } \\
-\quad \text { Organisation of the team can affect learning } \\
-\quad \text { Numbers of patients on lists affects learning }\end{array}$ & \\
\hline
\end{tabular}

majority of trainees learn traditionally by one-to-one mentorship. However, introduction of the European Working Time Directive and increase in numbers of trainees has led to a breakdown in the mentorship model and reduced opportunity to attend procedural lists. In 2009, Du Rand and Lewis presented results of a national survey of training in Bronchoscopy. "Learning curves" of average number of procedures required to become competent in different aspects of sampling in bronchoscopy were presented, but no information was gathered on different approaches to learning or factors affecting these curves. Indeed, there have been no studies examining "how" trainees learn in bronchoscopy. This study aimed to identify learning strategies currently being used by respiratory trainees in bronchoscopy and any helpful or unhelpful factors in this learning strategy.

Methods A qualitative study in two parts was conducted between April and June 2011. Firstly, a questionnaire to all respiratory trainees in the Northern Deanery. Thematic analysis was used to identify core themes and design the format for a subsequent focus group. The focus group was transcribed in full and two independent evaluators identified themes from the raw data. Triangulation was sought through a separate questionnaire to trainers. Validation of results was provided through local presentation of results.

Results 19 trainees and seven consultants completed questionnaires and five trainees took part in the focus group. Abstract P184 table 1 summarises themes identified. Few trainees had an explicit learning plan, however, trainees and trainers readily identified key steps involved in the primary approach of "learning from experience". Furthermore, many participants identified similar helpful and unhelpful factors within their own learning, their trainers' behaviour and the training environment. Many of these findings are supported by established learning theory and procedural-based learning (Kolb, 1984, Thuraisingam et al, 2006).

Conclusions Experience of the procedure is the key learning approach used by trainees in bronchoscopy. There are core steps within this that trainees and trainers can utilise to maximise learning. This is particularly important at the current time as training opportunities in bronchoscopy are reduced.

\section{REFERENCES}

1. Du Rand IA, Lewis RA. 'BTS bronchoscopy training survey 2009'. Thorax 2009:64 (Suppl IV):A75-4

2. Kolb DA. 'The Experiential learning theory of development'. Experiential Learning: experience as the source of learning and development. Englewood Cliffs, NJ: Prentice Hall, 1984:132-60.

3. Thuraisingam AI, MacDonald J, Shaw IS. 'Insights into endoscopy training: a qualitative study of learning experience'. Med Teach2006;28:453-9. 